\title{
Facebook in Vietnam: Uses, Gratifications \& Narcissism
}

\section{Brian McCauley, Sarah Gumbley, Giovanni Merola, Matthew McDonald, Truc Do}

RMIT University, Ho Chi Minh City, Vietnam

Email: brian.mccauley@rmit.edu.vn, sarah.gumbley@rmit.edu.vn,giovanni.merola@rmit.edu.vn,matthew.mcdonald@rmit.edu.vn, truc.donguyenthanh@rmit.edu.vn

How to cite this paper: McCauley, B., Gumbley, S., Merola, G., McDonald, M. and Do, T. (2016) Facebook in Vietnam: Uses, Gratifications \& Narcissism. Open Journal of Social Sciences, 4, 69-79.

http://dx.doi.org/10.4236/jss.2016.411006

Received: August 25, 2016 Accepted: November 22, 2016 Published: November 29, 2016

\begin{abstract}
The purpose of this study was to create a conceptual framework and to collect some pilot data in order to underpin future research on how the Vietnamese use Facebook in their day-to-day lives. A number of key points were observed in this study, which informed the framework. Firstly, there is a paucity of research on this topic, that Facebook users in Vietnam (population 90 million) rank as some of the heaviest consumers in the world, and Vietnamese cultural traditions and values need to be acknowledged given these differences when compared to other nations and how this might influence Facebook use. Given the studies focus on users, the theory on "uses and gratifications" was employed in order to understand how Facebook satisfies the needs of its Vietnamese users. An important component in this theory is the way in which Facebook allows posting of material related to the enhancement of the "self", which has the potential to satisfy ego driven needs in the form of narcissism. However, narcissism and its links with Facebook have only recently been systematically studied in Asian countries, predominately in China. In conclusion, the conceptual framework and analysis of the pilot data produced a number of interrelated constructs (e.g. socializing, social enhancement, entertainment) that provide a baseline or foundation from which a longer-term program of empirical research can be conducted on Facebook use in Vietnam ${ }^{1}$.
\end{abstract}

\section{Keywords}

Social Media, Narcissism, Uses and Gratification, Vietnamese Users, Conceptual Framework 


\section{Introduction}

Vietnamese Internet users rank as some of the heaviest consumers of Facebook in the world. To date, we could only find two studies that have investigated this large, growing and increasingly-influential market. One of these studies investigated the security and trust concerns of Vietnamese social network users [1]. The other study investigated young Vietnamese adults categorising them into different online personas (a social role or character). The study found three main types, the Outgoing Connector (finding information about people and establishing professional relationships with them in the offline world), the Reserved Trustor (interested in selective information about people at school and also events, products, and organisations) and the Threats Perceiver (who is a mixture of both) [2].

Given the paucity of research on Facebook users in Vietnam it is important that future research explore the unique nature of Vietnamese culture, and what influence this might have on Facebook user behaviors. The concept of culture has long defied definition, however, for the purpose of this study we define it as a society's leading thought patterns, modes of behaviour, beliefs and customs, or more simply the "unwritten rules of society" [3]. Culture makes groups cohesive through a shared sense of social identity. This influences communication in so far that it is often governed by ingroup norms that remain stable across time [3] [4]. Definitions of culture have also been applied to "cultures online" [5]. Like "offline cultures", online culture plays a role in influencing individuals through the internalization of certain values, some of these include "free sharing", "modifying", and "redistributing source materials" [5].

Research indicates that differences between Western and Asian samples are likely to arise when investigating social media use. One of the main differences here is the nature of identity formation [6] [7]. In Western cultures identities tend to be more individualistic, whereas Asian cultures are more collectivist. In collectivist cultures individuals typically view themselves as interdependent selves, part of a larger whole. Affiliation and belonging to family, region and nation are promoted and celebrated as important values. People from collectivist cultures are more likely to sacrifice their own needs for the sake of their extended family. Therefore people have a greater desire to maintain harmony and good relations with others through their interactions and communications. Individualistic cultures celebrate self-sufficiency, independence and the satisfaction of personal needs [6] [7]. Individualistic cultures promote open and frank interactions and communications between people, even when there is a risk this will lead to discord, disagreement and conflict. However, such outcomes may be viewed as positive as they have the potential to lead to more creative innovative solutions to issues and problems [3].

As a collectivist society, theoretically Vietnamese Facebook users are more likely to interact with it in ways that are going to be unlike their individualistic counterparts. Cultural background (e.g. collectivist versus individualistic) will also influence the narcissistic tendencies that are likely to emerge when using social media [8]. The literature indicates that Western culture and nations like the United States, have become more 
narcissistic over the last 30 years [9] [10] [11]. A similar phenomenon is only now just starting to be systematically researched in Asian nations such as China [12]. Nevertheless, it is difficult to say with any certainty if the "culture of narcissism" is becoming more commonplace in Asian nations until more research is conducted.

There is evidence to suggest that the way in which Asian people use the Asian social networking site Renren, which has a similar platform to Facebook, are more collectivistic in their behaviours, so that users perform more benevolent, conformity-oriented, hierarchical and less egalitarian ingroup sharing [5]. This is different to Facebook users in the West whose behaviours tend to be more individualistic such that there is a greater focus on the self; more self-talk, self-interest and self-centredness are expressed in posting and conversations [13].

\section{Uses and Gratifications of Social Media}

Social media such as Facebook, has many different definitions. Here it is defined as Web 2.0 applications enabling the creation, editing and dissemination of user-generated content [14]. In order to gain a deeper understanding of social media-related behaviors, the theory of "uses and gratifications" was developed. This theory assumes that media users are active participants in using and selecting media [8], as opposed to more critical theoretical explanations that tend to view media consumers as dupes who are controlled by it. Several studies have investigated the uses and gratifications of Facebook, the majority on Western samples, in particular college students [15] [16] [17] [18]. Most studies on social media have identified different uses and gratifications to date, however, there is no clear consensus as yet on the different constructs that inform this model given the complex, multi-faceted and still evolving behaviors that occur within the sphere of social media.

One area of research interest has been on the relationship between personality traits and Facebook use. For example, narcissism has become a commonly investigated trait. A narcissist is someone who possess an inflated view of self-an overblown sense of self-importance, they are often preoccupied with fantasies of success, brilliance, beauty and ideal love. They see themselves as better than others, are always on the look out to promote themselves to others in order to be seen in a positive light and often have problems in their relationships as they have little regard for others, unless they can benefit from them in some way [8] [19] [20] [21]. It is important to note that narcissism occurs along a spectrum. At the extreme pathological end are those people diagnosed with "narcissistic personality disorder", a condition that significantly impairs the life of its sufferers and which requires long-term psychiatric treatment if the patient is to learn how to live a normal life. At the less serious end, or what might be referred to as "subclinical" or "secondary narcissism", is a propensity for some individuals to behave in narcissistic ways, which is the focus of this study. Narcissism can also be healthy though, in children for example what is referred to as "primary narcissism" is viewed as an important part of the developmental process [20].

Investigations analysing the links between social networking and personality traits 
continue to increase as they provide insights on how individual differences are likely to influence the way people use these technologies [22] [23]. For example, on Facebook extraverts are more likely to post photographs of themselves with others at parties. Whereas conscientious individuals tend to post their resumes or count the number of visitors to their pages [24]. Social networking may also influence the formation of an individual's personality, that is their sense of self and identity.

Understanding the uses and gratifications of Facebook also has the potential to provide a deeper understanding of how people relate to others and if these online relations constitute a marker for distress and possible mental illness [24] [25]. Facebook has been found to gratify the needs of narcissists as it provides a platform for self-promotion and influencing behaviors (e.g. developing relationships for the purpose of individual gain) [22] [24]. Narcissists avoid interpersonal intimacy or meaningful (significant) longterm relational outcomes. Instead they initiate relationships using them to increase their perceived popularity, success and status in a way where they experience more instant forms of gratification. People who are more modest and less self-centred are less likely to use Facebook as a tool for self-promotion [24].

Differences in uses and gratifications have been found to occur along cultural lines [26]. For example, narcissistic tendencies can predict the frequency of Facebook status updates in Singaporean adolescents, while a similar study conducted in the United States found there was no relationship between Facebook updates and narcissistic tendencies [27].

Cross-cultural research on Facebook, related personality traits and how narcissistic tendencies are likely to manifest is still at a fledgling stage. Research linking personality traits (individual differences) with the uses and gratifications of social media have tended to be limited to Western samples [28]. A study comparing the personality traits of Vietnamese participants with those from a Western sample found some similarities and some differences [28]. These include similarities in the increases in agreeableness, conscientiousness, and emotional stability and decreases in extraversion whereas differences in age-conscientiousness and age-intellect relationship are noticeable.

\section{Toward a Framework for Conducting Empirical Research on Facebook in Vietnam}

Our analysis of the literature indicates that very little research has been conducted on Facebook use in Vietnam, and that what has been conducted is less than comprehensive. Given its popularity in Vietnam, future research has the potential to better understand the types of values that Facebook users internalise and how this might shape the formation of self-identity (e.g. does Facebook reinforce traditional Vietnamese values or does it influence the internalisation of newer less traditional values). Studying Facebook use also has the potential to test if the culture of narcissism is becoming an emerging phenomenon in Vietnam in the same way it has in the United States, as young people in Vietnam are being increasingly exposed to Western values through the consumption of Western media. If narcissism is found to be a growing personality trait 
in Vietnam, what are the implications for people's relationships and the health and wellbeing that flow from these.

A future study on Facebook uses and gratifications in Vietnam is required in order to provide a baseline or foundation from which a longer-term program of empirical research can be conducted. To begin with this requires a larger random sample that goes beyond the two previous studies that have been carried out on this topic in Vietnam [1] [2], from which it is not possible to draw any firm conclusions (generalisations). Secondly, a more sophisticated multi-dimensional set of constructs developed from the uses and gratifications literature needs to be tested, with the aim of exploring what concepts within this broad perspective provide a deeper interpretation of Vietnamese user behaviours. In line with this aim a conceptual framework has been developed (see Figure 1 \& Appendix 1). This framework represents a synthesis of the literature from which key constructs were derived. This conceptual framework is designed to cast a wide net over the phenomenon initially, so that more targeted research can be conducted in the future by eliminating constructs which fail to be pertinent.

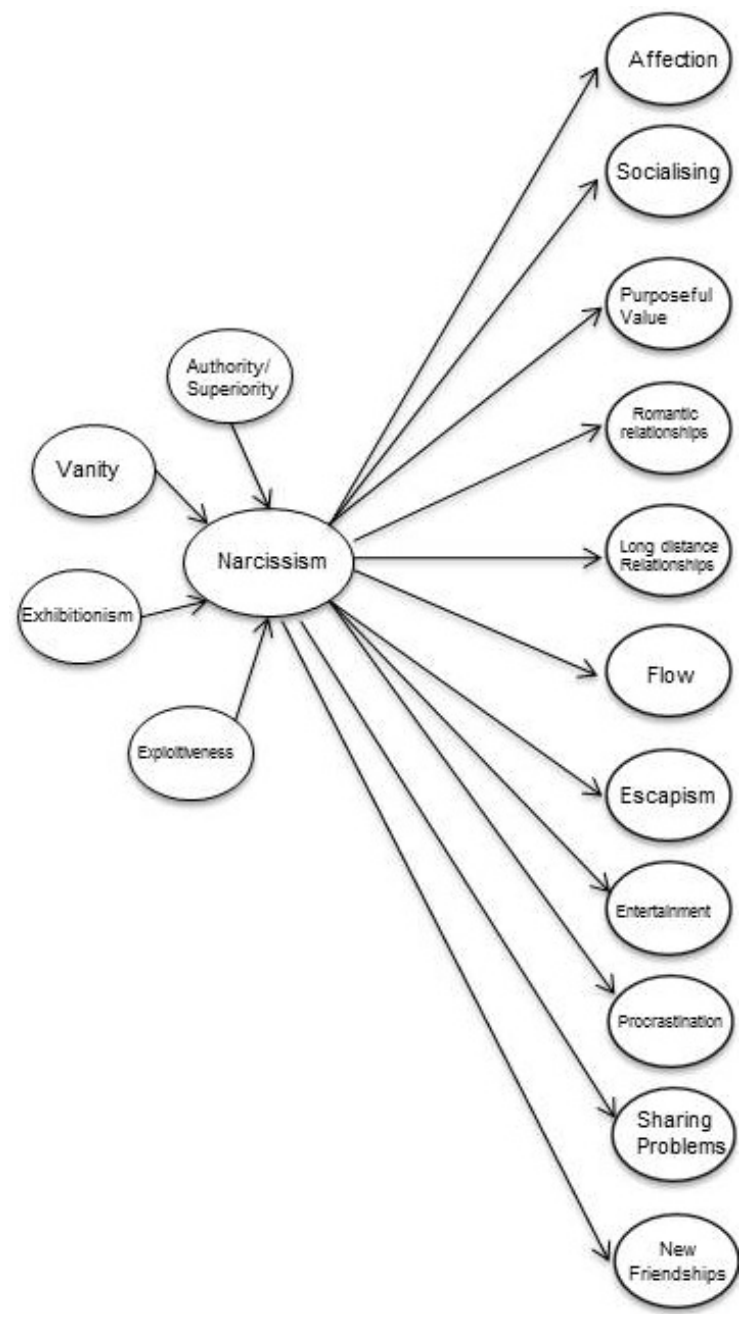

Figure 1. Conceptual framework. 
From the synthesis of the literature 17 discrete but interrelated constructs were identified. These include: "Socialising" [16], which reflects one of the primary uses for social networks. Further gratifications related to socialising include affection, sharing problems and satisfying the need for social information [17]. Reference [29] investigated the motives for Facebook use among young adults and found that maintaining long distance "relationships", establishing "new friendships" and "initiating romantic relationships" are all significant motivations for use. "Purposive value"-one of the five key values determining the purpose of virtual communities [15], is a construct that suggests people use Facebook to obtain predetermined "informational or instrumental value". Facebook is increasingly being used for "entertainment purposes" [15] and also as a means of "procrastination" [30]. It is a vehicle for "escapism" [31] and a means in which to achieve "flow" states [32] - a state of total immersion in an activity that represents the optimal balance between the use of skills and challenges to meet these-which is a powerful form of gratification.

Given some of the important issues around Facebook use and narcissism that have been identified in this paper, the conceptual framework has been designed to examine how its various components are linked to social media use [23]. An established scale, the Narcissistic Personality Inventory (NPI) [33] that has been used in previous social media studies was incorporated [8]. The NPI contains fifteen validated items for measuring narcissism. The four main components of the scale include "authority/superiority", "vanity", "exploitativeness" and "exhibitionism", all of which have been shown to have a high level of utility when exploring narcissism in relation to Facebook usage [8].

Figure 1 overleaf illustrates the conceptual model.

\section{References}

[1] Sriratanaviriyakul, N., Nkhoma, M., Felipe, A.L., Cao, T.K. and Tran, Q.H. (2014) Vietnamese Privacy Concerns and Security in Using Online Social Networks. International Journal of Electronic Security and Digital Forensics, 6, 306-318. https://doi.org/10.1504/IJESDF.2014.065740

[2] Dang-Pham, D., Ptttayachawan, S. and Nkhoma, M. (2015) Demystifying Online Personas of Vietnamese Young Adults on Facebook: A Q-Methodology Approach. Australasian Journal of Information Systems, 19. https://doi.org/10.3127/ajis.v19i0.1204

[3] Hofstede, G.J., Jonker, C.M. and Verwaart, T. (2012) Cultural Differentiation of Negotiating Agents. Group Decision and Negotiation, 21, 79-98. https://doi.org/10.1007/s10726-010-9190-x

[4] Jenkins, R. (2014) Social Identity. Routledge, London.

[5] Qiu, L., Lin, H. and Leung, A.K.Y. (2013) Cultural Differences and Switching of In-Group Sharing Behavior between an American (Facebook) and a Chinese (Renren) Social Networking Site. Journal of Cross-Cultural Psychology, 44, 106-121. https://doi.org/10.1177/0022022111434597

[6] Markus, H.R. and Kitayama, S. (1991) Culture and the Self: Implications for Cognition, Emotion, and Motivation. Psychological Review, 98, 224-253. https://doi.org/10.1037/0033-295X.98.2.224

[7] Triandis, H.C. (1995) Individualism \& Collectivism (New Directions in Social Psychology). 
Westview Press, Boulder.

[8] Leung, L. (2013) Generational Differences in Content Generation in Social Media: The Roles of the Gratifications Sought and of Narcissism. Computers in Human Behavior, 29, 997-1006. https://doi.org/10.1016/j.chb.2012.12.028

[9] Lasch, C. (1979) The Culture of Narcissism: American Life in an Age of Diminishing Expectations. W.W. Norton, New York.

[10] McDonald, M., Wearing, S. and Ponting, J. (2008) Narcissism and Neo-Liberalism: Work, Leisure and Alienation in an Era of Consumption. Loisir et Societe (Society and Leisure), 30, 489-510. https://doi.org/10.1080/07053436.2007.10707762

[11] Twenge, J.M. and Campbell, W.K. (2009) The Narcissism Epidemic: Living in the Age of Entitlement. Atria, New York.

[12] Huajian, C., Kwan, V.S.Y. and Sedikides, C. (2012) A Sociocultural Approach to Narcissism: The Case of Modern China. European Journal of Personality, 26, 529-539. https://doi.org/10.1002/per.852

[13] Jackson, L.A. and Wang, J.L. (2013) Cultural Differences in Social Networking Site Use: A Comparative Study of China and the United States. Computers in Human Behavior, 29, 910-921. https://doi.org/10.1016/j.chb.2012.11.024

[14] Constantinides, E. (2014) Foundations of Social Media Marketing. Procedia-Social and Behavioral Sciences, 148, 40-57. https://doi.org/10.1016/j.sbspro.2014.07.016

[15] Cheung, C.M., Chiu, P.Y. and Lee, M.K. (2011) Online Social Networks: Why Do Students Use Facebook?. Computers in Human Behavior, 27, 1337-1343. https://doi.org/10.1016/j.chb.2010.07.028

[16] Park, N., Kee, K.F. and Valenzuela, S. (2009) Being Immersed in Social Networking Environment: Facebook Groups, Uses and Gratifications, and Social Outcomes. Cyberpsychology \& Behavior, 12, 729-733. https://doi.org/10.1089/cpb.2009.0003

[17] Quan-Haase, A. and Young, A.L. (2010) Uses and Gratifications of Social Media: A Comparison of Facebook and Instant Messaging. Bulletin of Science, Technology \& Society, 30, 350-361. https://doi.org/10.1177/0270467610380009

[18] Raacke, J. and Bonds-Raacke, J. (2008) MySpace and Facebook: Applying the Uses and Gratifications Theory to Exploring Friend-Networking Sites. Cyberpsychology \& Behavior, 11, 169-174. https://doi.org/10.1089/cpb.2007.0056

[19] Campbell, W.K. and Foster, J.D. (2007) The Narcissistic Self: Background, an Extended Agency Model, and Ongoing Controversies. In: Constantine, S. and Steven, J.S., Eds., The Self, Psychology Press, Oxford, 115-138.

[20] Holmes, J. (2001) Narcissism. Icon Books, Cambridge.

[21] McCann, J.T. and Biaggio, M.K. (1989) Narcissistic Personality Features and Self-Reported Anger. Psychological Reports, 64, 55-58. https://doi.org/10.2466/pr0.1989.64.1.55

[22] Ryan, T. and Xenos, S. (2011) Who Uses Facebook? An Investigation into the Relationship between the Big Five, Shyness, Narcissism, Loneliness, and Facebook Usage. Computers in Human Behavior, 27, 1658-1664. https://doi.org/10.1016/j.chb.2011.02.004

[23] Panek, E.T., Nardis, Y. and Konrath, S. (2013) Mirror or Megaphone?: How Relationships between Narcissism and Social Networking Site Use Differ on Facebook and Twitter. Computers in Human Behavior, 29, 2004-2012. https://doi.org/10.1016/j.chb.2013.04.012

[24] Buffardi, L.E. and Campbell, W.K. (2008) Narcissism and Social Networking Web Sites,. Personality and Social Psychology Bulletin, 34, 1303-1314. https://doi.org/10.1177/0146167208320061 
[25] Carpenter, C.J. (2012) Narcissism on Facebook: Self-Promotional and Anti-Social Behaviour. Personality and Individual Differences, 52, 482-486.

https://doi.org/10.1016/j.paid.2011.11.011

[26] Ong, E.Y., et al. (2011) Narcissism, Extraversion and Adolescents' Self-Presentation on Facebook. Personality and Individual Differences, 50, 180-185.

https://doi.org/10.1016/j.paid.2010.09.022

[27] Bergman, S.M., Fearrington, M.E., Davenport, S.W. and Bergman, J.Z. (2011) Millennials, Narcissism, and Social Networking: What Narcissists Do on Social Networking Sites and Why. Personality and Individual Differences, 50, 706-711. https://doi.org/10.1016/j.paid.2010.12.022

[28] Walton, K.E., et al. (2013) Cross-Sectional Personality Differences from Age 16-90 in a Vietnamese Sample. Journal of Research in Personality, 47, 36-40. https://doi.org/10.1016/j.jrp.2012.10.011

[29] Tosun, L.P. (2012) Motives for Facebook Use and Expressing “True Self” on the Internet. Computers in Human Behavior, 28, 1510-1517. https://doi.org/10.1016/j.chb.2012.03.018

[30] Myrick, J.G. (2015) Emotion Regulation, Procrastination, and Watching Cat Videos Online: Who Watches Internet Cats, Why, and to What Effect? Computers in Human Behavior, 52, 168-176. https://doi.org/10.1016/j.chb.2015.06.001

[31] McCauley, B. (2014) Intrinsic Motivations of Mobility, Play and Enjoyment: The Smartphone Game Experience. PhD Thesis, RMIT University.

[32] Chang, Y.P. and Zhu, D.H. (2012) The Role of Perceived Social Capital and Flow Experience in Building Users' Continuance Intention to Social Networking Sites in China. Computers in Human Behavior, 28, 995-1001. https://doi.org/10.1016/j.chb.2012.01.001

[33] Raskin, R.N. and Hall, C.S. (1979) A Narcissistic Personality Inventory. Psychological Reports, 45, 590-590. 


\section{Appendix 1: Full Scales}

I use Facebook to:

Socializing (Park et al. 2009)

To get peer support from others

To meet interesting people

To feel like I belong to a community

To talk about something with others

To stay in touch with people I know

Purposeful Value (Cheung et al. 2011)

To get information

To learn how to do things

To provide others with information

To contribute to a pool of information

To generate ideas

To negotiate or bargain

To get someone to do something for me

To solve problems

To make decisions

Social Enhancement (Cheung et al. 2011)

To impress

To feel important

Entertainment (Cheung et al. 2011)

To be entertained

To play

To relax

To pass time away when bored

Managing long-distance relationships (Tosun 2012)

To reconnect with people you've lost contact with

To find out what old friends are doing now

To maintaining relationships with people you may not get to see very often

To find people you have not seen for a while

To connecting with people you otherwise would have lost contact with

To keep in touch with friends living in long-distances

Initiating romantic relationships (Tosun 2012)

For online dating

To meet new romantic partners

To open up my romantic feelings to someone that I would not say in person 
Establishing new relationships (Tosun 2012)

To meet likeminded people

To find new friends

To meet with people who are more interesting than the people whom you meet face to face

Affection (Quan-Haase \& Young 2010)

To thank people

To let people know I care about them

To show others encouragement

To help others

To show others that I am concerned about them

Share problems (Quan-Haase \& Young 2010)

Because I need someone to talk to or be with

Because I just need to talk about my problems sometimes

To forget about my problems

Social information (Quan-Haase \& Young 2010)

To feel involved with what's going on with other people

Escapism (McCauley 2014)

So I can escape from reality

So I can get away from what I am doing

So I can forget about work/study

Because it helps me unwind

Procrastination (Myrick 2015)

To find an excuse for not doing something else.

To postpone starting in on things I don't like to do.

To avoid doing an unpleasant task or activity.

Flow (Chang \& $\mathrm{Zu}$ 2012)

I feel time passes quickly

I never think of other things

I am entirely absorbed

Narcissism Measures (Leung 2013) Authority/superiority

1. I am an extraordinary person.

2. I can usually talk my way out of anything.

3. I see myself as a good leader.

4. I am more capable than other people. 
5. I know that I am good because everybody keeps telling me so.

6. I have a natural talent for influencing people.

7. I would prefer to be a leader.

\section{Exhibitionism}

8. I like to be complimented.

9. I insist upon getting the respect that is due me.

10. I like to be the center of attention.

\section{Exploitativeness}

11. I find it easy to manipulate people.

12. I will never be satisfied until I get all that I deserve.

13. I can make anybody believe anything I want.

\section{Vanity}

14. I like to look at my body.

15. I like to look at myself in the mirror.

Submit or recommend next manuscript to SCIRP and we will provide best service for you:

Accepting pre-submission inquiries through Email, Facebook, LinkedIn, Twitter, etc. A wide selection of journals (inclusive of 9 subjects, more than 200 journals)

Providing 24-hour high-quality service

User-friendly online submission system

Fair and swift peer-review system

Efficient typesetting and proofreading procedure

Display of the result of downloads and visits, as well as the number of cited articles Maximum dissemination of your research work

Submit your manuscript at: http://papersubmission.scirp.org/

Orcontact jss@scirp.org 